\title{
PRAEFATIO EDITORIS.
}

Cum quid de pristino Theogoniae Hesiodeae statu sentirem in peculiari commentatione academica nuper ita exposuissem, ut codicum fidem ad textum restituendum sufficere iudicarem, dummodo de Hesiodo vel alio unius carminis solo auctore somniare desineremus, hanc me sententiam firmaturum esse hoc ipso textu confisus sum, quem neque stropharum divisione neque correctionibus obelisve vexatum eruditorum examini subiicio. Quodsi C. F. Schoemannum, virum de Hesiodea poesi optime meritum, Theogoniam nostram ut unius poetae carmen ex ea ipsa vetustae poesis officina Attica, ex qua Homerica quoque carmina collecta atque digesta olim prodierant, deduxisse non ignoro, compositionem quidem Theogoniae aetati et officinae illi deberi libens et ipse concedo; de carminum autem quae in Theogonia continentur origine aliter sentire me iubent diversa, cum Hesiodi aliorumve poetarum, tum compositoris Pisistratei censorisque ipsi acqualis vestigia. Igitur in nova Theogoniae hac recensione Hesiodi aliorumque poetarmi carmina eal ex quibus 
Onomacritus aliusve Pisistrato aequalis compositor veterum carminum theogonicum hunc, ut ita dicam, cyclum formasse videtur, in sectiones divisi, sectionum argumenta descripsi, genuinum cuiusque sectionis textum litteris maioribus excudi curavi, minores autem et minimos typos ita adhibui ut compositoris additamenta a recensionis posterioris laciniis distinguerem; denique varietatem lectionis, quatenus commodum id videbatur, notavi. Integram enim lectionum, correctionum, vindiciarum copiam si quis requiret, Muetzellii commentarius, Goettlingii Lennepiique editiones, Hermanni opuscula, Schoemanni dissertationes in promptu erunt.

Scribebam Berolini die X mensis Maii MDCCCLVI. 